\title{
A sevoflurane induction of anesthesia with gradual reduction of concentration is well tolerated in elderly patients
}

\author{
[L'induction de l'anesthésie au sévoflurane, avec une réduction graduelle de la \\ concentration, est bien tolérée par les patients âgés]
}

Shigeki Yamaguchi MD PhD, Tomohito Ikeda MD, Koji Wake MD, Yasuhisa Okuda MD PhD, Toshimitsu Kitajima MD PhD

Purpose: To establish the appropriate inhalation induction technique using a high concentration of sevoflurane in the elderly.

Methods: Forty-five patients, aged 70-79-yr-old, were randomly divided into three groups: I) Group I: anesthesia was induced with propofol $2 \mathrm{mg} \cdot \mathrm{kg}^{-1}$ and sevoflurane $2 \%(n=15)$; 2) Group II: anesthesia was induced with a three- minute inhalation of sevoflurane $8 \%$; 3) Group III: anesthesia was induced with inhalation of sevoflurane using a gradual reduction technique (8, 6, 4\% for each minute). In Groups II and III, a modified vital capacity inhalation induction was performed. Mean arterial pressure (MAP), heart rate $(\mathrm{HR})$ and oxygen saturation $\left(\mathrm{SpO}_{2}\right)$ were measured continuously during induction. In addition, induction time and adverse events related to anesthetic induction were recorded.

Results: The induction time in Group I was significantly shorter than that in Groups II and III ( $P<0.05)$. However, there was no difference in the induction time between Groups II and III. In Groups II and III, the majority of patients required additional breaths. In comparison with the other groups, stability of MAP was maintained in Group III. The variations of HR in all groups were small. During induction, no patient experienced a decrease in $\mathrm{SpO}_{2}$ below 96\%, except for two patients in Group I. Severe respiratory adverse events were not observed. Other adverse events were similar in all groups.

Conclusions: Our results suggest that a high concentration sevoflurane induction using a gradual reduction technique may be an acceptable alternative to standard iv induction in elderly patients.
Objectif : Réaliser la technique appropriée d'induction par inhalation en utilisant une forte concentration de sévoflurane chez des patients âgés.

Méthode : Quarante-cinq patients de 70-79 ans, ont été répartis de façon aléatoire en trois groupes : I) groupe I : anesthésie induite avec $2 \mathrm{mg} \cdot \mathrm{kg}^{-1}$ de propofol et du sévoflurane à $2 \%(n=15)$; 2) groupe II : anesthésie induite avec l'inhalation de sévoflurane à $8 \%$ pendant 3 min ; 3) groupe III : anesthésie induite avec l'inhalation de sévoflurane selon la technique de réduction graduelle de la concentration (8, 6, 4 $\%$ pour chaque minute). Dans les groupes II et III, une induction par inhalation, avec modification de la capacité vitale, a été réalisée. La tension artérielle moyenne (TAM), la fréquence cardiaque (FR) et la saturation du sang en oxygène $\left(\mathrm{SpO}_{2}\right)$ ont été mesurées en continu pendant l'induction. De plus, le temps nécessaire à l'induction et les événements indésirables reliés à l'induction anesthésique ont été notés.

Résultats : Le temps d'induction a été significativement plus court dans le groupe I que dans les groupes II et III $(P<0,05)$. Aucune différence de temps d'induction n'a été relevée entre les groupes II et III. Dans ces groupes II et III, la majorité des patients ont eu besoin de ventilation supplémentaire. Comparativement aux autres groupes, la stabilité de la TAM a été maintenue dans le groupe III. Les variations de FC ont été faibles dans tous les groupes. Pendant l'induction, aucun patient n'a subi de baisse de la $\mathrm{SpO}_{2}$ en dessous de $96 \%$, sauf deux patients du groupe I. Aucune complication respiratoire sévère n'a été observée. Les autres événements indésirables ont été comparables d'un groupe à l'autre.

Conclusion : Nos résultats montrent qu'une induction avec une forte concentration de sévoflurane, selon une technique de réduction graduelle, peut remplacer l'induction iv habituelle de façon acceptable chez les patients âgés.

From the Department of Anesthesiology, Dokkyo University School of Medicine, Mibu, Tochigi, Japan.

Address correspondence to: Dr. Shigeki Yamaguchi, Department of Anesthesiology, Dokkyo University School of Medicine, Mibu,

Tochigi 321-0293, Japan. Phone: 81-282-861111; Fax: 81-282-860478; E-mail: shigeki@dokkyomed.ac.jp

Accepted for publication January 24, 2002.

Revision accepted September 9, 2002. 


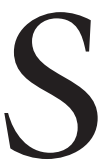

EVOFLURANE is an ideal agent for inhalation induction of anesthesia. Sevoflurane for inhalation induction has improved the conditions of anesthetic induction in comparison with other volatile agents. ${ }^{1-3}$ Vital capacity inhalation of a high concentration of sevoflurane has been described as useful and safe. ${ }^{1-5}$ Compared to the conventional inhalation induction technique using a gradual increase of concentration, a high concentration sevoflurane induction produced a rapid induction and reduced adverse effects. ${ }^{4}$ Furthermore, sevoflurane induction provided additional advantages such as good cardiovascular stability, ${ }^{3,6,7}$ smooth transition between induction and maintenance, ${ }^{6,8}$ and rapid onset of non-depolarizing muscle relaxant ${ }^{9}$ compared with $i v$ induction.

There have been many reports focusing on young volunteers and patients, so that vital capacity inhalation induction with a high concentration of sevoflurane has become a widespread alternative to $i v$ induction. However, little is known about it effects in the elderly ${ }^{10}$ in whom cardiovascular and respiratory reserve may be limited. ${ }^{10,11}$ Improving the technique may make it possible to perform an inhalation induction with a high concentration of sevoflurane in the elderly.

The aim of the present study, therefore, was to establish an appropriate technique for high concentration induction of anesthesia with sevoflurane in the elderly. We tested and compared three induction techniques: 1) iv induction with propofol; 2) high concentration sevoflurane induction using the conventional technique; and 3) high concentration sevoflurane induction with a new technique using a gradual reduction of concentration (GRC). We hypothesized that a high concentration sevoflurane induction with GRC would produce a rapid and smoother induction while maintaining cardiovascular stability and avoiding adverse events in elderly patients.

\section{Methods}

After obtaining the approval of the hospital Ethics Committee and patient informed consent, 45 patients, aged 70-79 yr, ASA II, scheduled for elective surgery were studied. The surgical procedures were otorhinolaryngologic, oral, or orthopedic and involved minimal blood loss. Before the study, the patients' cardiovascular and respiratory condition were evaluated using chest $x$-ray, electrocardiography (ECG), echocardiography, spirometry and oxygen saturation. Exclusion criteria included severe or uncontrolled heart disease (NYHA classification II or more), documented coronary artery disease, asthma with an attack within a month and severe respiratory disease with less than $94 \%$ oxygen saturation $\left(\mathrm{SpO}_{2}\right)$ while breathing room air. Those with hepatic, renal, or neuromuscular disease were excluded. In addition, patients were excluded if systolic or diastolic blood pressure were above 180 or $110 \mathrm{mmHg}$, respectively. Patients were within $15 \%$ of ideal body weight. Observations were made by an anesthesiologist blinded to the induction technique and induction of anesthesia was performed by an anesthesiologist familiar with the vital capacity induction technique.

Patients were randomly divided into three groups using a sealed envelope. 1) Group I $(n=15)$ : anesthesia was induced by $i v$ injection of $2 \mathrm{mg} \cdot \mathrm{kg}^{-1}$ propofol followed by inhalation of sevoflurane $2 \%$ in $100 \%$ oxygen; 2$)$ Group II ( $n=15)$ : aneshesia was induced by a modified vital capacity technique with sevoflurane $8 \%$ in $100 \%$ oxygen, and three minutes after inhalation of sevoflurane $8 \%$ the vaporizer setting was adjusted to $2 \%$; 3$)$ Group III $(n=15)$ : anesthesia was induced initially with sevoflurane $8 \%$, and the sevoflurane concentration was decreased by $2 \%$ every minute until the $2 \%$ vaporizer setting was reached.

Patients were not premedicated. On arrival in the operating room, an $i v$ cannula was inserted, and cardiovascular and respiratory monitoring was commenced with ECG, pulse oxymetry and non-invasive arterial blood pressure. After the start of anesthetic induction, end-tidal concentration of carbon dioxide $\left(\mathrm{PETCO}_{2}\right)$ was measured continuously.

All patients were breathing room air before induction of anesthesia. In Group I, the circle system of the anesthetic machine (A-VSEVO; Aladin Cassette for Sevoflurane with Quik Fil ${ }^{\mathrm{TM}}$, Datex-Omeda, Sweden) was primed for five minutes with sevoflurane $2 \%$ in oxygen at $6 \mathrm{~L} \cdot \mathrm{min}^{-1}$ fresh gas flow. After injection of propofol $2 \mathrm{mg} \cdot \mathrm{kg}^{-1}$ and loss of consciousness, a mask with anesthetic circle system was applied on the patient's face and assisted ventilation was initiated. Ventilation was controlled after the patient ceased breathing.

In Groups II and III, a modified vital capacity induction with high concentration sevoflurane ${ }^{10}$ was employed to induce anesthesia. The circle system of the anesthetic machine was primed for five minutes with sevoflurane $8 \%$ in oxygen at $6 \mathrm{~L} \cdot \mathrm{min}^{-1}$ fresh gas flow. Patients were instructed to breathe out to residual volume and the face mask was applied tightly. Patients took a vital capacity breath of sevoflurane $8 \%$ in oxygen which they were to hold as long as possible. If necessary, second and third vital capacity breaths were taken. After loss of consciousness, assisted ventilation was started via the face mask, and the ventilation was controlled after the patient ceased breathing.

Vecuronium $0.1 \mathrm{mg} \cdot \mathrm{kg}^{-1}$ was administered intravenously in order to facilitate tracheal intubation in all groups. Ventilation was controlled after tracheal intu- 
TABLE I Demographic data

\begin{tabular}{llll}
\hline & $\begin{array}{l}\text { Group I } \\
(n=15)\end{array}$ & $\begin{array}{l}\text { Group II } \\
(n=15)\end{array}$ & $\begin{array}{l}\text { Group III } \\
(n=15)\end{array}$ \\
\hline Age (yr) & $75 \pm 3$ & $74 \pm 4$ & $75 \pm 3$ \\
Sex (males/females) & $8 / 7$ & $7 / 8$ & $9 / 6$ \\
Height (cm) & $157 \pm 10$ & $156 \pm 7$ & $154 \pm 10$ \\
Body weight (kg) & $52 \pm 10$ & $52 \pm 7$ & $53 \pm 9$ \\
Number of patients with: & & & \\
Hypertension & 11 & 10 & 10 \\
Diabetes & 2 & 2 & 3 \\
Heart disease & 6 & 4 & 6 \\
$\quad$ Arrhythmia & 3 & 2 & 1 \\
$\quad$ Ischemic heart disease & 2 & 3 & 2 \\
$\quad$ Valve disease & 1 & 2 & 2 \\
\hline
\end{tabular}

TABLE II Induction times

\begin{tabular}{llll}
\hline & $\begin{array}{l}\text { Group I } \\
(n=15)\end{array}$ & $\begin{array}{l}\text { Group II } \\
(n=15)\end{array}$ & $\begin{array}{l}\text { Group III } \\
(n=15)\end{array}$ \\
\hline $\begin{array}{l}\text { Time to loss of } \\
\text { consciousness (sec) }\end{array}$ & $36 \pm 13$ & $58 \pm 11 \dagger$ & $61 \pm 18 \dagger$ \\
$\begin{array}{l}\text { Time to disappearance of } \\
\text { eyelash reflex (sec) }\end{array}$ & $43 \pm 15$ & $67 \pm 13 \dagger$ & $72 \pm 21 \dagger$ \\
\hline
\end{tabular}

Group I: anesthesia was induced with propofol $2 \mathrm{mg} \cdot \mathrm{kg}^{-1}$ and sevoflurane $2 \%$. Group II: anesthesia was induced with a threeminute inhalation of sevoflurane $8 \%$. Group III: anesthesia was induced with inhalation of sevoflurane using a gradual reduction technique. Values expressed as mean \pm SD. $\dagger P<0.05$ vs Group I.

bation, and $\mathrm{PETCO}_{2}$ was maintained between 35 to $40 \mathrm{mmHg}$ during the study.

Two induction times were recorded as follows: 1) from the start of induction to loss of consciousness; and 2) from the start of induction to disappearance of eyelash reflex. The loss of consciousness was defined as no response to verbal commands repeated at ten-second intervals until the patient failed to respond. The disappearance of eyelash reflex was determined at tensecond intervals.

Heart rate (HR), mean arterial pressure (MAP), and $\mathrm{SpO}_{2}$ were recorded before induction (baseline) and every minute subsequently. In addition, ECG monitoring of lead II and $\mathrm{V}_{5}$ with continuous ST-segment analysis were applied.

The adverse events associated with anesthetic induction were recorded.

In the postoperative period, patients who received a sevoflurane induction completed a questionnaire on their feelings regarding the odour of sevoflurane. In addition, all patients were asked whether they would be willing to receive the same induction again in the future.
Data are expressed as mean \pm SD. Statistical analyses of the data were performed by one-way or two-way analysis of variance (ANOVA) with post hoc multiple comparison (Bonferroni correction). Statistical significance was assumed at $P<0.05$.

\section{Results}

There were no differences in the demographic data among the three groups (Table I). Although most patients in all groups had underlying medical conditions such as hypertension and heart disease, these were controlled medically. All operations were scheduled in the morning and patients received their usual medication two hours before anesthesia. No patients received $\alpha$-antagonists, which might have affected cardiovascular stability during anesthetic induction.

\section{Induction times}

The induction times are shown in Table II. The time to loss of consciousness and disappearance of eyelash reflex was significantly shorter in Group I than in the other groups. There was no significant difference between Groups II and III.

\section{Cardiovascular stability}

Changes of HR in all groups are shown in Figure 1. There was no significant difference in HR at baseline between the three groups. There were no significant variations of $\mathrm{HR}$ compared to baseline in all groups during induction. Immediately after intubation, HR increased significantly in Group I, but not in Groups II and III.

Changes of MAP in all groups are shown in Figure 2. There was no difference in MAP at baseline among the three groups. In Group I, MAP decreased immediately after the injection of propofol. In Group II, MAP decreased gradually with the inhalation of sevoflurane. In Groups I and II, decreases of 30 $\mathrm{mmHg}$ or more from baseline values in MAP were observed. In Group III, MAP decreased by 20 $\mathrm{mmHg}$. In all groups, MAP increased after intubation. The increase of MAP in Group I was significantly larger than in Groups II and III. After intubation, MAP decreased in Group II compared to Group III.

Three patients presented arrhythmia during induction in Group II. Although two of those patients had premature ventricular contractions and one had atrial premature contractions, all arrhythmias disappeared within a few minutes, without any treatment. No arrhythmia was noted during induction in Groups II and III.

No patient suffered any ST changes in all groups. 


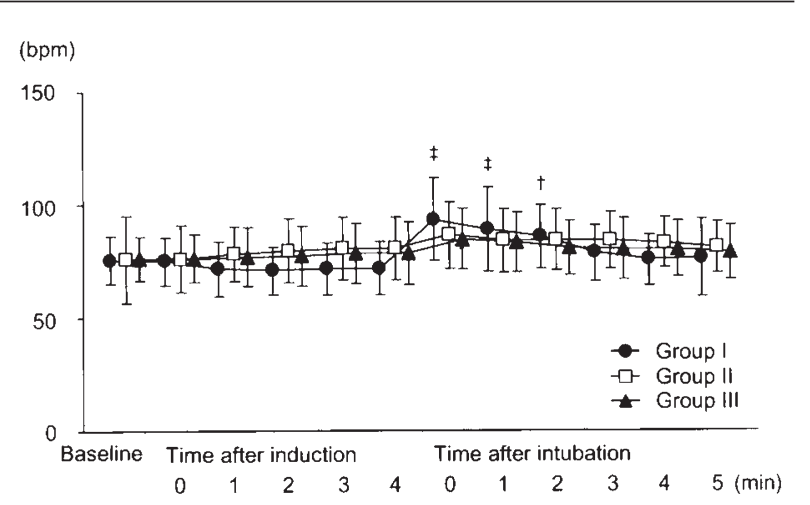

FIGURE 1 Changes in heart rate during anesthetic induction. Group I: anesthesia was induced with propofol $2 \mathrm{mg} \cdot \mathrm{kg}^{-1}$ and sevoflurane $2 \%$. Group II: anesthesia was induced with a threeminute inhalation of sevoflurane $8 \%$. Group III: anesthesia was induced with inhalation of sevoflurane using a gradual reduction technique. Values expressed as mean $\pm \mathrm{SD}$. $\dagger P<0.05$ vs baseline; $\ddagger P<0.01$ vs baseline.

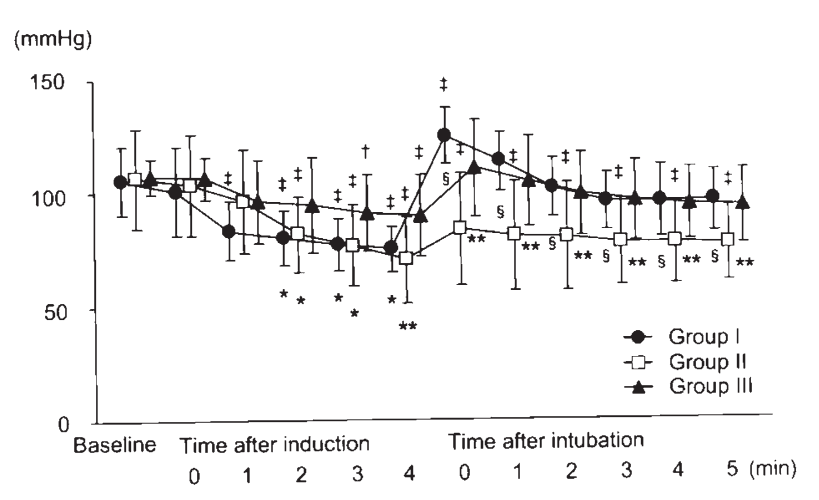

FIGURE 2 Changes in mean arterial pressure during anesthetic induction. See Figure 1 and text for details on groups. Values expressed as mean $\pm \mathrm{SD} .{ }^{*} P<0.05$ vs Group III; ${ }^{*} P<0.01$ vs Group III; $\mathbb{S} P<0.05$ vs Group II. $\dagger P<0.05$ vs baseline; $\ddagger P<$ 0.01 vs baseline.

\section{Respiratory conditions}

$\mathrm{SpO}_{2}$ at baseline in Groups I, II and III were $96.0 \pm$ $0.5 \%, 95.8 \pm 0.7 \%$ and $96.1 \pm 1.0 \%$, respectively $(P=$ NS). SpO2 remained above $96 \%$ in all patients except for two patients in Group I $(P=\mathrm{NS})$. $\mathrm{SpO}_{2}$ increased above $98 \%$ within one minute after the start of mechanical ventilation.

\section{Adverse events}

The overall incidence of adverse effects during induction was similar in all groups and none were severe. Two patients presented transient breath holding immediately after injection of propofol in Group I. In Groups II and III, a patient coughed during induction with sevoflurane, but ventilation was not disturbed and coughing resolved spontaneously. Two patients had hiccups in Group II which disappeared after the administration of vecuronium. No patient complained about the odour of sevoflurane.

\section{Patient satisfaction}

In Groups II and III, single breath induction was successful in only two patients in each group. The majority of patients in Groups II and III required additional vital capacity breaths. Patients were generally satisfied with their induction and there were no significant differences between groups. All patients were willing to receive the same induction in the future.

\section{Discussion}

We have shown that inhalation induction with high concentration sevoflurane may be used successfully in elderly patients. High concentration sevoflurane induction provided a rapid and smooth induction, although most patients required additional vital capacity breaths. Furthermore, $\mathrm{SpO}_{2}$ was well maintained, without severe adverse effects on respiration. Compared to $i v$ induction with propofol, a high concentration sevoflurane induction with a GRC technique improved cardiovascular stability during anesthetic induction. However, traditional high concentration sevoflurane induction (without GRC) reduced MAP to an extent similar to $i v$ induction with propofol. In contrast to the induction of anesthesia with propofol and $2 \%$ sevoflurane, high concentration sevoflurane induction with either the traditional technique or the GRC technique blunted the cardiovascular response to tracheal intubation.

Vital capacity inhalation induction requires the cooperation of patients. Elderly patients may not be able to hold a vital capacity breath for a sufficient length of time. Possible explanations include that breathing in elderly patients may not be sufficiently coordinated to achieve a reliable vital capacity because of the difference between total lung capacity and residual volume. Another is that leaks around the mask may occur when the patient is edentulous. Walpole et al. ${ }^{10}$ indicated that elderly patients might have difficulty in holding a breath for $30 \mathrm{sec}$ or more and reported a modified vital capacity inhalation induction. The technique allowed patients to take a 
second and third vital capacity breaths if required. In the present study, although most patients required additional breaths, induction times in our elderly patients were similar to those reported previously in young volunteers and patients. ${ }^{1-8}$

Severe respiratory adverse events were not observed with high concentration sevoflurane induction. Although there were a few patients with a cough or hiccup associated with sevoflurane, our findings are similar to previous reports focusing on young volunteers and patients. ${ }^{1-8}$ Furthermore, breath holding and a decrease in $\mathrm{SpO}_{2}$ below $96 \%$ occurred in two patients who received an iv induction, but not in patients who received high concentration sevoflurane induction.

Most patients had cardiovascular disease such as hypertension, diabetes and heart disease. Inhalation induction with high concentration sevoflurane was described to provide cardiovascular stability with a rapid induction in young volunteers and patients. ${ }^{1-8}$ Several studies in young volunteers and patients have demonstrated that HR increased slightly or not and that arterial blood pressure decreased 10 to $20 \%$ after inhalation induction with high concentrations of sevoflurane. ${ }^{1-8}$ However, elderly patients are more sensitive to cardiovascular depression with volatile agents. ${ }^{10,12,13}$ Cardiovascular instability may contribute to perioperative myocardial ischemia and cardiac morbidity in these patients. ${ }^{14-16}$ Precautions should be taken to avoid adverse events during anesthetic induction. Walpole et al. ${ }^{10}$ showed that the mean reduction of systolic arterial pressure from preinduction values was $30 \pm 13 \%$ in elderly patients. Nathan et al. ${ }^{17}$ reported severe hypotension during high concentration sevoflurane induction in elderly patients with hypertension. In both of the above studies, patients inhaled $8 \%$ sevoflurane for approximately three or $4.5 \mathrm{~min}$ during induction. On the other hand, Cheong et al. ${ }^{18}$, Gravel et al. ${ }^{19}$ and Djaiani et $a .^{20}$ studied inhalation induction with sevoflurane in elderly patients scheduled for coronary artery bypass graft surgery and described that it offered a rapid and smooth induction with hemodynamic stability. In the three above-mentioned studies, patients inhaled high concentrations of sevoflurane only until the eyelid reflex disappeared. The authors combined short-term sevoflurane inhalation with opioids, to avoid awareness or adverse cardiovascular responses to intubation. In the present study, no opioid was administered before intubation. Instead, the GRC technique was employed in Group III. This technique was designed to maintain an adequate depth of anesthesia during induction. It significantly attenuated the decrease in MAP compared to a traditional inhalation induction or $i v$ induction with propofol. Furthermore, cardiovascular responses to intubation with the GRC technique were significantly lesser than that with in induction with propofol, and comparable to that with a traditional inhalation induction. These results suggest that the GRC technique may provide adequate anesthesia without cardiovascular instability during induction even if opioids are not used.

In conclusion, we evaluated high concentration sevoflurane induction with two different techniques in the elderly, compared to $i v$ induction. High concentration sevoflurane induction using a GRC technique provided cardiovascular and respiratory stability during induction without adverse effects, compared to other techniques. This inhalation technique may be an acceptable alternative to standard $i v$ induction.

\section{References}

1 Yurino $M$, Kimura $H$. Vital capacity breath technique for rapid anaesthetic induction: comparison of sevoflruane and isoflurane. Anaesthesia 1992; 47: 946-9.

2 Yurino $M$, Kimura $H$. Vital capacity rapid inhalation induction technique: comparison of sevoflurane and halothane. Can J Anaesth 1993; 40: 440-3.

3 Hall JE, Oldham TA, Stewart JIM, Harmer M. Comparison between halothane and sevoflurane for adult vital capacity induction. Br J Anaesth 1997; 79: 285-8.

4 Yurino $M$, Kimura $H$. Induction of anesthesia with sevoflurane, nitrous oxide, and oxygen: a comparison of spontaneous ventilation and vital capacity rapid inhalation induction (VCRII) techniques. Anesth Analg 1993; 76: 598-601.

5 Philip BK, Lombard LL, Roaf ER, Drager LR, Calalang I, Philip JH. Comparison of vital capacity induction with sevoflurane to intravenous induction with propofol for adult ambulatory anesthesia. Anesth Analg 1999; 89: 623-7.

6 Thwaites A, Edmends S, Smith I. Inhalation induction with sevoflurane: a double-blind comparison with propofol. Br J Anaesth 1997; 78: 356-61.

7 Nishiyama T, Aibiki M, Hanaoka K. Haemodynamic and catecholamine changes during rapid sevoflurane induction with tidal volume breathing. Can J Anaesth 1997; 44: 1066-70.

8 Ti LK, Chow MYH, Lee TL. Comparison of sevoflurane with propofol for laryngeal mask airway insertion in adults. Anesth Analg 1999; 88: 908-12.

9 Yamaguchi S, Egawa H, Okuda K, Mishio M, Okuda Y, Kitajima T. High concentration sevoflurane induction of anesthesia accelerates onset of vecuronium neuromuscular blockade. Can J Anesth 2001; 48: 34-7.

10 Walpole R, Logan M. Effect of sevoflurane concentra- 
tion on inhalation induction of anaesthesia in the elderly. Br J Anaesth 1999; 82: 20-4.

11 Jin F, Chung F. Minimizing perioperative adverse events in the elderly. Br J Anaesth 2001; 87: 608-24.

12 Nakajima $R$, Nakajima $\Upsilon$, Ikeda K. Minimum alveolar concentration of sevoflurane in elderly patients. $\mathrm{Br} \mathrm{J}$ Anaesth 1993; 70: 273-5.

13 Mapleson $W W$. Effect of age on MAC in humans: a meta-analysis. Br J Anaesth 1996; 76: 179-85.

14 Mangano DT. Perioperative cardiac morbidity. Anesthesiology 1990; 72: 153-84.

15 Mangano DT, Browner WS, Hollenberg M, London MJ, Tubau JF, Tateo IM. Association of perioperative myocardial ischemia with cardiac morbidity and mortality in men undergoing noncardiac surgery. The Study of Perioperative Ischemia Research Group. N Engl J Med 1990; 323: 1781-8.

16 Slogoff S, Keats AS. Does perioperative myocardial ischemia lead to postoperative myocardial infarction? Anesthesiology 1985; 62: 107-14.

17 Nathan N, Vial G, Benrhaiem M, Peyclit A, Feiss P. Induction with propofol taget-concentration infusion vs. $8 \%$ sevoflurane inhalation and alfentanil in hypertensive patients. Anaesthesia 2001; 56: 248-71.

18 Cheong KF, Choy JML. Sevoflurane-fentanyl versus etomidate-fentanyl for anesthetic induction in coronary artery bypass graft surgery patients. J Cardiothor Vasc Anesth 2000; 14: 421-4.

19 Gravel NR, Searle NR, Taillefer J, Carrier M, Roy M, Gagnon L. Comparison of the hemodynamic effects of sevoflurane anesthesia induction and maintenance vs TIVA in CABG surgery. Can J Anesth 1999; 46: 240-6.

20 Djaiani GN, Hall J, Pugh S, Peaston RT. Vital capacity inhalation induction with sevoflurane: an alternative to standard intravenous induction for patients undergoing cardiac surgery. J Cardiothor Vasc Anesth 2001; 15: 169-74. 